\title{
Mucosal-Associated Invariant T-Cell
}

National Cancer Institute

\section{Source}

National Cancer Institute. Mucosal-Associated Invariant T-Cell. NCI Thesaurus. Code C115217.

A T-cell subtype bearing a semi-invariant T-cell receptor and restricted by the major histocompatibility complex related molecule MR1. These cells occupy peripheral tissues and are noted for their reactivity ag ainst various microorg anisms of either bacterial or fungal origin. 